\title{
Bond-Slip Mechanisms of Hooked-End Steel Fibers in Self-Compacting Concrete
}

\author{
Vítor M.C.F. Cunha ${ }^{1, a}$, Joaquim A.O. Barros ${ }^{1, b}$ and José M. Sena-Cruz ${ }^{1, c}$ \\ ${ }^{1}$ Dep. Civil Engineering, University of Minho, Guimarães, Portugal \\ a vcunha@civil.uminho.pt, ${ }^{b}$ barros@civil.uminho.pt, ${ }^{c}$ jsena@civil.uminho.pt
}

Keywords: Pullout, hooked-fibers, self-compacting concrete, analytical model, back-analysis.

\begin{abstract}
The experimental results of hooked-end steel fibers pullout tests on a self-compacting concrete medium are presented and discussed in this work. The influence of fiber embedment length on the fiber pullout behavior is studied. The role of the end hook of the fiber on the overall pullout behavior is also investigated by carrying out tests with fibers without its end hook, in order to separate the contribution of the frictional bond component from those derived from the mechanisms provided by the end hook of the fiber. Finally, the experimental bond-slip relationships are modeled by an analytical model.
\end{abstract}

\section{Introduction}

Steel fiber reinforced self-compacting concrete (SFRSCC) is a relatively recent composite material which congregates the benefits of the self-compacting concrete technology with the profits derived from the fiber addition to a brittle cementitious matrix. In the fresh state, SFRSCC homogeneously spreads due to its own weight, without any additional compaction energy, having to fulfill high demands with regard to filling and passing ability, as well as segregation resistance. On the other hand, in the hardened state, the addition of fibers to brittle cementitious matrix contributes, mostly, to the improvement of the impact resistance and the energy absorption capacity [1], since the fibers that bridge the cracks will allow stress transfer between crack planes and retard the crack opening propagation.

In fiber reinforced concrete (FRC) material, the interface between fiber and cement paste is the weak link of its micro-structure. Therefore, the study of the behavior of fiber-paste interface is important for understanding the mechanical behavior of such composites. The effectiveness of a given fiber as a medium of stress transfer is often assessed using a single fiber pullout test, where the load applied to the fiber is monitored as a function of the fiber slip [2-3]. In spite of the belief sometimes held, that no correlation exists between the behavior of a fiber in a single fiber pullout test and its behavior in a real composite material, single fiber pullout tests provide relevant information for the development new advanced FRC products of optimized properties. In addition, although there is not an ideal test or model to fully predict the mechanical behavior of steel fiber reinforced concrete - even for the basic case of uniaxial tension, since the relationships obtained from this test differ for different combination of fiber type, fiber content and concrete properties the fiber reinforcement mechanisms in a single pullout test, can help to understand the overall behavior of a composite material tested under uniaxial tension. Furthermore, with the advance of the computing facilities, the possibility of simulating the structural behavior of FRC elements based on the modeling of its constituents and their interactions is becoming a reality, which introduces a new interest on the behavior of fiber-matrix interaction.

\section{Experimental Results}

The experimental program here presented is comprised of two groups of pullout tests. The first one is constituted of three series of hooked fibers, each consisting of six specimens. The second group is composed of three series of smooth fibers, each one with three specimens. To assess the influence 
of the fiber embedded length (Lb) on the pullout response, series of tests with 10,20 and $30 \mathrm{~mm}$ of Lb were tested. Each series was assigned with a code name, $(i)$ Lb(j), where $i$ can be $S$ or $H$ and stands, respectively, for smooth and hooked fiber, and $j$ is the embedded length (10, 20 or $30 \mathrm{~mm})$. In all performed tests only DRAMIX RC-80/60-BN hook-ended steel fibers were used. The adopted fiber had a length of $60 \mathrm{~mm}$, a $0.75 \mathrm{~mm}$ diameter, an aspect ratio of 80 and a yield stress of $1100 \mathrm{MPa}$. To perform the smooth fiber pullout tests, the end hook of the RC-80/60-BN fiber was cut with pliers.

Concrete mixture and test specimen. The materials used in the composition of the steel fiber reinforced self-compacting concrete, SFRSCC, were: cement (C) CEM I 42.5R, limestone filler (LF), superplasticizer (SP) of third generation based on polycarboxilates (Glenium ${ }^{\circledR} 77 \mathrm{SCC}$ ), water (W), three types of aggregates (fine river sand (FS), coarse river sand (CS) and crushed granite 5$12 \mathrm{~mm}(\mathrm{CA})$ ). The method used for defining the composition of the SFRSCC, the mixing procedure and other properties of the SFRSCC in the fresh state can be found elsewhere [4]. Table 1 includes the composition that has best fitted self-compacting requirements for the adopted content of fibers, (Cf). Remark that, in Table 1, WS is the water necessary to saturate the aggregates and $\mathrm{W} / \mathrm{C}$ is the water/cement ratio. The WS parcel was not used to compute the $\mathrm{W} / \mathrm{C}$ ratio.

The pullout tests on single steel fibers were performed using cylindrical concrete specimens. The diameter and height of each specimen was $80 \mathrm{~mm}$. To produce the specimens, a special mould was used to cast several pullout specimens simultaneously, allowing a correct placement of the fiber and keeping the desired embedded length and inclination angle [5]. After casting, the concrete slab was cured at a temperature of $20^{\circ} \mathrm{C}$ and a relative humidity of about $95 \%$. After 30 days, the concrete was demoulded, and cylindrical specimens containing each one single fiber were drilled out from the slab. The fiber pullout tests were performed at approximately 180 days. The compressive strength of the concrete was accessed by three cubic specimens with an edge length of $150 \mathrm{~mm}$. The average value of the compressive strength, at the fiber pullout testing age, was $83.4 \mathrm{MPa}$ with a coefficient of variation of $0.9 \%$.

Table 1- Final composition for $1 \mathrm{~m}^{3}$ of SFRSCC.

\begin{tabular}{c|cccccccccc}
\hline $\begin{array}{c}\text { Cf } \\
{[\mathrm{kg}]}\end{array}$ & $\begin{array}{c}\text { Paste / total } \\
\text { volume }[\%]\end{array}$ & $\begin{array}{c}\mathrm{C} \\
{[\mathrm{kg}]}\end{array}$ & $\begin{array}{c}\mathrm{LF} \\
{[\mathrm{kg}]}\end{array}$ & $\begin{array}{c}\mathrm{W} \\
{\left[\mathrm{dm}^{3}\right]}\end{array}$ & $\begin{array}{c}\text { WS } \\
{\left[\mathrm{dm}^{3}\right]}\end{array}$ & $\begin{array}{c}\text { SP } \\
{\left[\mathrm{dm}^{3}\right]}\end{array}$ & $\begin{array}{c}\text { FS } \\
{[\mathrm{kg}]}\end{array}$ & $\begin{array}{c}\text { CS } \\
{[\mathrm{kg}]}\end{array}$ & $\begin{array}{c}\text { CA } \\
{[\mathrm{kg}]}\end{array}$ & W/S \\
\hline 30 & 0.34 & 359.4 & 312.2 & 96.9 & 64.7 & 6.9 & 108.2 & 709.4 & 665.2 & 0.29 \\
\hline
\end{tabular}

Test set-up. The pullout tests were performed on a servo-hydraulic Lloyd LR30K machine with a capacity of $30 \mathrm{kN}$. To acquire the applied force with more accuracy, a HBM S9 load cell with a capacity of $5 \mathrm{kN}$ was attached to the machine test frame. The single-sided specimen was mounted in a steel frame attached to the testing rig (see Fig. 1a), and the protruding end of the steel fiber is fastened to a standard "Lloyd" grip which allowed a secure hold.
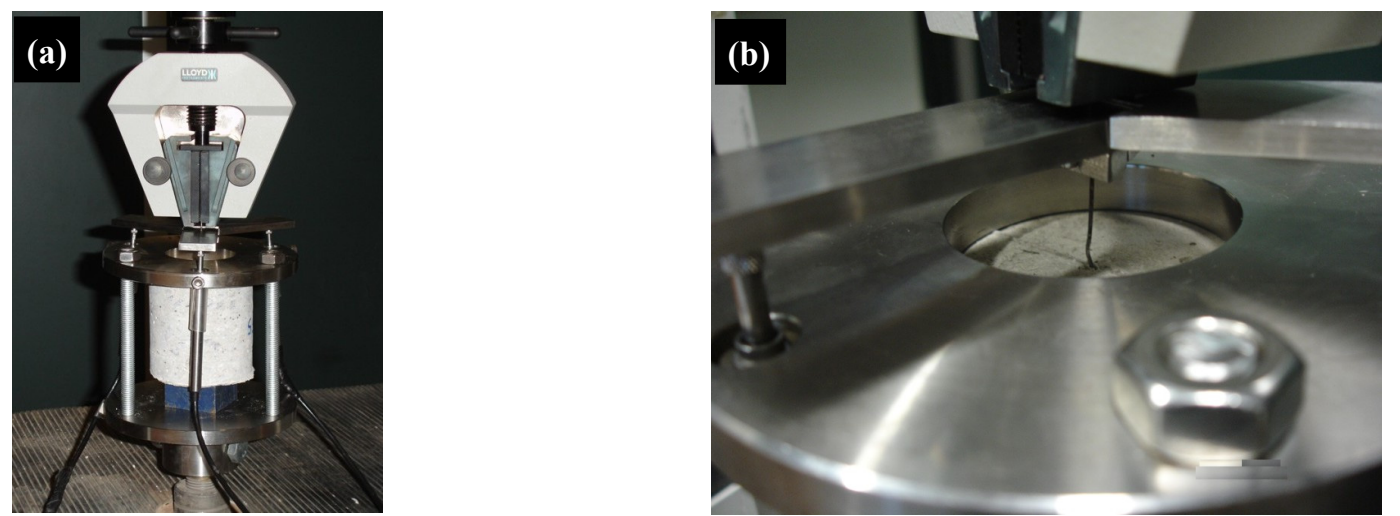

Fig. 1- Configuration of the single fiber pullout test: (a) general view and (b) detailed view of the aluminum plate fixed to the fiber. 
For the measurement of the fiber pullout slip, three LVDT's (linear stroke $+/-5 \mathrm{~mm}$ ) were used. To exclude measuring deformations of the testing rig and fiber slip at the grip, the LVDT's were fixed at the upper steel ring and touching the bottom surface of an aluminum plate fixed to the fiber (detail in Fig. 1(b)). The closed-loop displacement control was performed by the testing machine internal displacement transducer, applying a displacement rate of $10 \mu \mathrm{m} / \mathrm{s}$.

Fiber pullout behavior. In Fig. 2 are depicted the average pullout load-slip curves for the tested series. Due to technical problems, the series S_Lb10 could not be correctly tested, therefore they are not presented.

The pre-peak branch of the pullout-slip curves for both hooked and smooth fibers is made up of a linear and non-linear part. The first one is associated with the elastic bonding, whereas the nonlinear part starts with the micro-cracking of the interface, corresponding to the debonding process. The non-linear part of the ascending branch is more pronounced in hooked fibers. The lost of stiffness associated to the pre-peak nonlinear branch is justified by the irrecoverable deformation component of the fiber and the surround paste at the zone of the end hook, when this part of the fiber starts being straightened. On the other hand, for smooth fibers the non-linear part of the ascending branch has a relative small amplitude, since starts very close to the peak load. In smooth fibers, after the peak load is attained a sudden drop is observed, which corresponds to an abrupt increase of damage at the fiber-paste interface (unstable debond). Afterwards, fiber-paste friction is the commanding mechanism of the pullout behavior. In this part of the post-peak branch, the load decreases with the increase of slip, since the available frictional area decreases, as well as the roughness of the failure surface. On the other hand, the post-peak load decay in hooked fibers was not so abrupt than in smooth fibers, since with the increase of the slip the fiber mechanical anchorage starts to become progressively mobilized. At an approximately $4.5 \mathrm{~mm}$ slip (corresponding approximately to the straightened hook length), the pullout process occurs under frictional resistance in similitude to smooth fibers.

In general, for each type of fiber analyzed the configuration of the pullout load-slip curve was similar, regardless the fiber embedded length but, as expected, the peak load $\left(\mathrm{P}_{\max }\right)$ the slip at peak load ( $\left.\mathrm{s}_{\text {peak }}\right)$ and the dissipated energy $\left(\mathrm{G}_{1 \mathrm{~mm}}\right.$ - energy dissipated up to a slip of $\left.1 \mathrm{~mm}\right)$ increased with $\mathrm{Lb}$ (see Table 2, where average values are included, as well as the correspondent coefficient of variation, $\mathrm{CoV}$ ). The influence of $\mathrm{Lb}$ on the values of these parameters was more significant on the smooth fibers, since an increase of more than $100 \%$ on $\mathrm{P}_{\max }$ and $\mathrm{G}_{1 \mathrm{~mm}}$ occurred, increasing Lb from 20 to $30 \mathrm{~mm}$, while relative small increments were registered for the hooked end fibers. In fact, for hooked fibers the increment of $\mathrm{Lb}$ from 10 to $30 \mathrm{~mm}$ provided an increase on the $\mathrm{P}_{\max }$ and $\mathrm{G}_{1 \mathrm{~mm}}$ of in $20 \%$ and $18 \%$, respectively. These results demonstrate that the pullout response of hooked fibers at given embedment length is predominantly influenced by the mobilization and straightening of the hook, which is in accordance with published findings $[2,6]$.

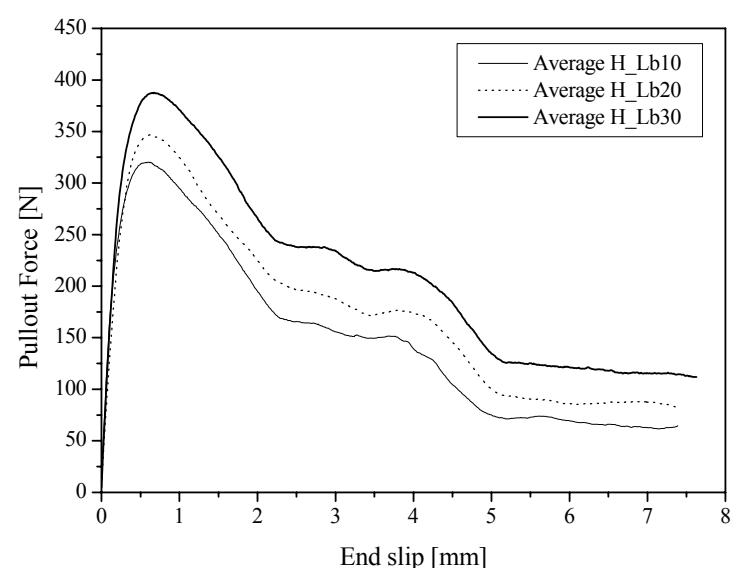

(a)

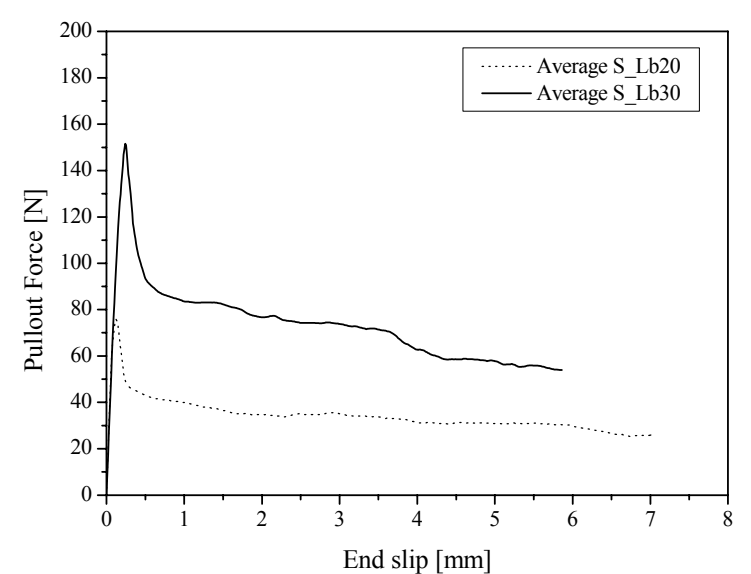

(b)

Fig. 2- Average pullout load slip curves for: (a) hooked and (b) smooth fibers. 
Table 2- Average pullout results.

\begin{tabular}{c|cc|cc|cc}
\hline \multirow{2}{*}{ Series } & \multicolumn{2}{|c|}{$\mathrm{P}_{\max }$} & \multicolumn{2}{c|}{ Speak } & \multicolumn{2}{c}{$\mathrm{G}_{1 \mathrm{~mm}}$} \\
& Avg. $[\mathrm{N}]$ & CoV $[\%]$ & Avg. [mm] & CoV & Avg. [N.m] & CoV \\
\hline H_Lb10 & 321.8 & 5.6 & 0.59 & 11.8 & 0.273 & 5.6 \\
H_Lb20 & 347.8 & 2.8 & 0.65 & 14.4 & 0.283 & 3.6 \\
H_Lb30 & 388.2 & 1.6 & 0.69 & 8.7 & 0.322 & 2.4 \\
S_Lb20 & 77.4 & 2.0 & 0.12 & 9.4 & 0.045 & 2.0 \\
S_Lb30 & 155.2 & 9.7 & 0.25 & 11.0 & 0.095 & 9.7 \\
\hline
\end{tabular}

In Fig. 3 is depicted the contribution of the end hook mechanism on the overall pullout behavior. The mechanical component of bond (curve 3 in Fig.3) was obtained by subtracting the average curve of the hooked series (curve 1 in Fig.3) to the correspondent average curve of the smooth series (curve 2 in Fig.3). Comparing the curves 3 obtained for both the $20 \mathrm{~mm}$ and $30 \mathrm{~mm}$ embedment lengths, respectively Figs. 3(a) and 3(b), it can be observed that the curves are extremely similar. This also reveals that if the full mobilization of the hook is attained, the mechanical component of the hook is not influenced by the embedment length. This will not be true if the embedment length is smaller than the length of the hooked end [6], which is not the case of the present work.

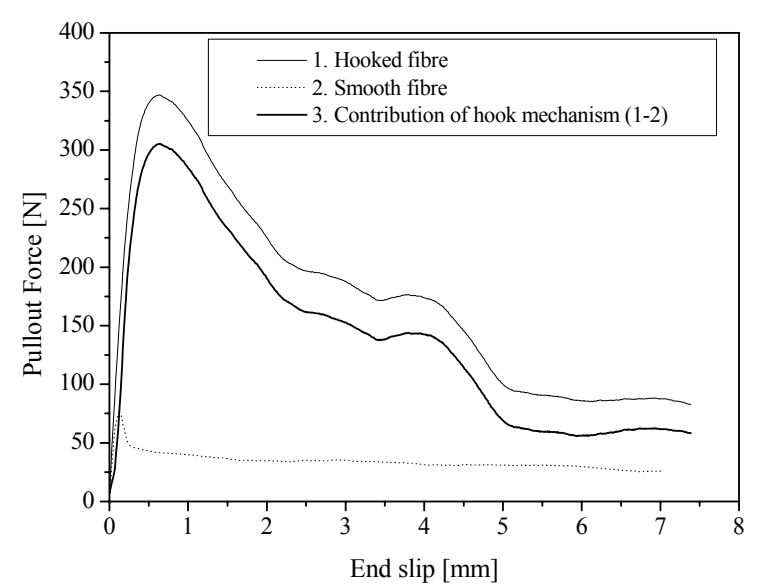

(a)

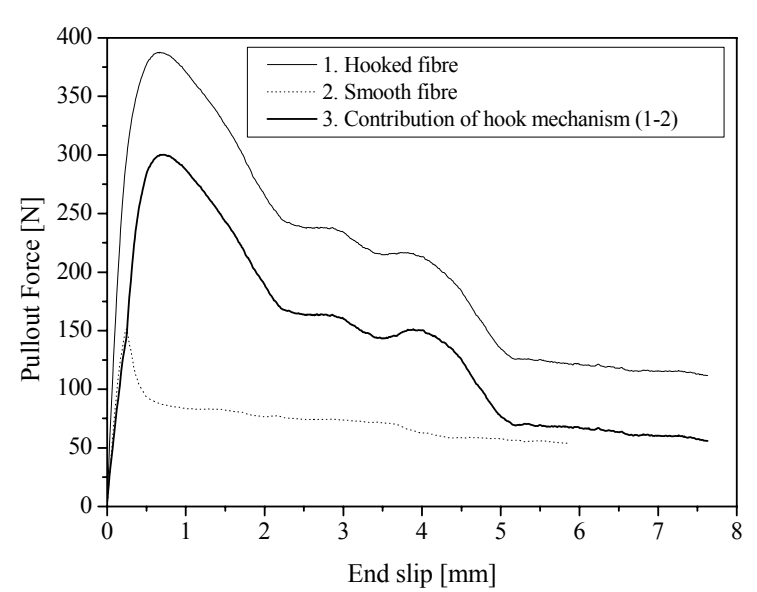

(b)

Fig. 3- Contribution of the end hook on the overall pullout behavior of hooked-end fibers with an embedment length of: (a) $20 \mathrm{~mm}$ and (b) $30 \mathrm{~mm}$.

\section{Analytical Simulation}

The second order differential equation that governs the local bond phenomena of the fiber-matrix interface is given by:

$$
\frac{d^{2} s}{d x^{2}}=\frac{P_{f}}{E_{f} \cdot A_{f}} \cdot \tau(s(x)) .
$$

where, $P_{f}, E_{f}$ and $A_{f}$ are the fiber perimeter, elasticity modulus and area, respectively. In this equation $\tau(s(x))$ is the local bond slip shear stress acting on the contact surface between fiber and concrete, and $s$ is the slip. Eq. 1 was obtained from the equilibrium of an infinitesimal length $d x$ of a fiber bonded to a concrete matrix, and neglecting the concrete deformability in the slip determination. The pullout load-slip relationship was determined using an energy approach [5]. Solution of Eq. 1 was obtained numerically using the Runge-Kutta-Nystrom method. A detailed description and derivation of the theoretical relationships and numerical tools used in the model can 
be found elsewhere [5]. Performing a back-analysis, the parameters of the local bond stress-slip law that best fitted the experimental pullout load-slip curves of the smooth series were obtained.

In Fig. 4(a) is depicted the local bond law used and the parameters obtained in the back-analysis. On the other hand, in the series H_Lb20 and H_Lb30, the adhesive bond component was modeled with the parameters obtained in the back-analysis corresponding to the series S_Lb20 and S_Lb30, whereas the mechanical bond provided by the hook was modeled with the average of curves " 3 " depicted in Figs. 3(a) and 3(b). In Fig. 4(b) are represented the average experimental curves and correspondent analytical curves. The analytical curves modeled quite well the experimental curves for the series with an embedded length of 20 and $30 \mathrm{~mm}$.

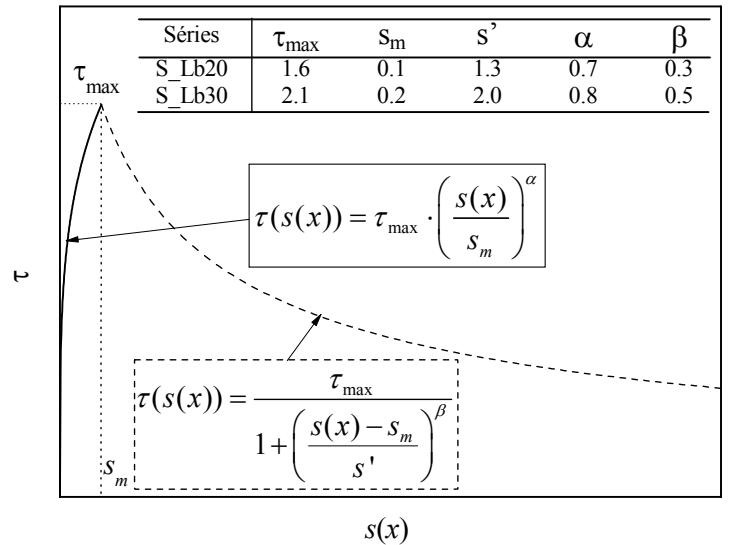

(a)

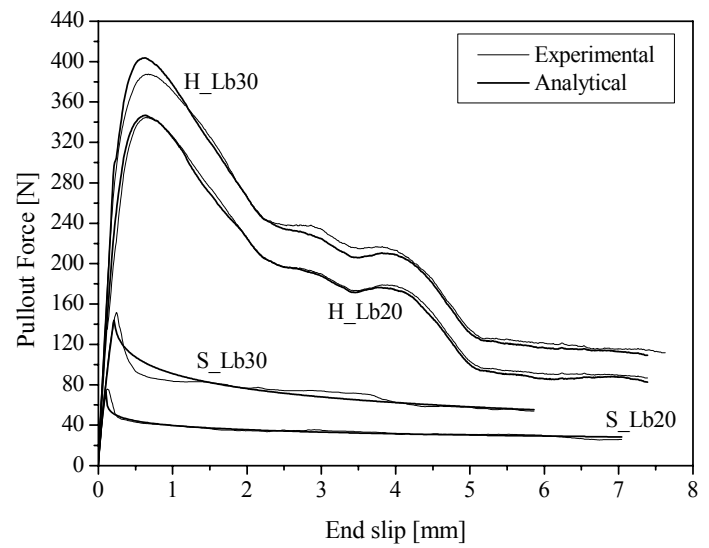

(b)

Fig. 3- (a) Local bond stress-slip law and (b) Experimental and analytical curves.

\section{Conclusions}

The experimental results of hooked-end steel fibers pullout tests on a self-compacting concrete medium were presented and discussed. The influence of fiber embedded length on the peak load, slip at peak load and toughness up to a slip of $1 \mathrm{~mm}$ was more significant on smooth fibers than on hooked fibers. Nevertheless, all these parameters increased with the embedment length for both, smooth and hooked fibers. The mechanical contribution of the end hook, on the overall pullout behavior, was not influenced by the embedment length. Finally, the experimental pullout load-slip relationships were modeled quite well by the proposed analytical model.

\section{Acknowledgements}

The study reported in this paper is part of the research program "PaberPro - conception and implementation of a system for the production of lightweight panels of SFRSCC" supported by FEDER and MCT, and promoted by ADI. The authors wish to thank the materials generously supplied by Bekaert (fibers), SECIL (cement), Degussa (superplasticizer), and Comital (limestone filler). The first author wishes also to thank the grant SFRH/BD/18002/2004, provided by FCT.

\section{References}

[1] ACI 544.1R: ACI Technical Report (1997).

[2] A. E. Naaman and H. Najm: ACI Mater. Jour. Vol. 88-2 (1991), p. 135.

[3] N. Banthia and J. Tottier: ACI Mater. Jour. Vol. 91-5 (1994), p. 435.

[4] J. A. O Barros. E. N. B. Pereira, S.P.F. Santos: Lightweight panels of steel fiber reinforced selfcompacting concrete (Journal of Materials in Civil Engineering, 19-4, 2007). 
[5] V. Cunha, J. Barros and J. Sena Cruz: Pullout behaviour of hooked-end steel fibres in selfcompacting concrete (Technical report 07-DEC/E06, University of Minho, Portugal, 2007).

[6] P. Robins, S. Austin and P. Jones: Mater. \& Struct. Jour. Vol.35 (2002), p. 434. 